\title{
O TERCIÁRIO EM PROCESSO OU SUAS DIFERENTES FORMAS HISTÓRICAS DE MANIFESTAÇÃO
}

\author{
Marconi Gomes da Silva ${ }^{1}$ \\ Márcia Maria Bezerra ${ }^{2}$ \\ Denílson da Silva Araújo ${ }^{3}$
}

RESUMO: $O$ artigo tem como objetivo central analisar a gênese e o desenvolvimento do setor terciário sob a luz da teoria marxista. Como ferramentas analíticas foram utilizados os conceitos de divisão do trabalho no âmbito da manufatura e no âmbito da sociedade, dando especial relevo ao movimento interativo e complementar de ambos os conceitos, entendidos como instrumentos essenciais para a compreensão do movimento do capital em direção ao setor terciário. A análise proposta levou a algumas sugestões de conclusão: o setor terciário deve ser analisado com rigorosa observância das condições concretas de organização do capital em seu interior; nos países desenvolvidos, o setor terciário manifesta maior atratividade ao capital, maior autonomia para o crescimento e modernização quando comparado com o setor terciário da periferia, dependente do capital internacional e do Estado nacional para a produção e oferta de produtos e serviços; apesar da incipiência econômico-estrutural do terciário na periferia do sistema capitalista, foi possível concluir que nesses espaços sociais o terciário foi e é de fundamental importância para a acumulação do capital em geral e que vem se transformando, mesmo que de forma relativa, em importante locus de valorização do capital, de criação de receita para os entes federativos e, dentre outros pontos positivos, da criação de empregos formais e informais que em boa mediada amortecem as clássicas crises de reprodução do sistema.

Palavras-Chave. Setor terciário; Serviços; Divisão social do trabalho; Industrialização dos serviços; Paradigma marxista.

ABSTRACT: The main objective of the article is to analyze development and the tertiary sector in the light of Marxist theory. As analytical tools, the concepts of division of labor were used within the scope of the manufacturer and within society, giving special relief to the interactive and complementary movement of both concepts, presented as essential instruments for understanding the movement of capital towards the sector tertiary. A proposed analysis had some suggestions for

\footnotetext{
${ }^{1}$ Doutor em Ciências Sociais. Professor do Departamento de Economia (DEPEC) da Universidade Federal do Rio Grande do Norte (UFRN). Natal. Rio Grande do Norte. Brasil. E-mail: marconi.br62@gmail.com. ORCID: https://orcid.org/0000-0002-2382-5094

2 Doutora em Economia. Professora do Programa de Pós-Graduação em Economia da Universidade Federal do Rio Grande do Norte (PPECO-UFRN), Natal. Rio Grande do Norte. Brasil. E-mail: marciabezerra2910@gmail.com .ORCID: https://orcid.org/0000-0001-9364-7003.

${ }_{3}^{3}$ Professor do Departamento de Economia da Universidade Federal do Rio Grande do Norte (UFRN) e integrante dos seguintes grupos: Grupo de Estudos e Pesquisas em Espaço, Trabalho, Inovação e Sustentabilidade (GEPETIS), Núcleo de Estudos Multissetoriais, Estratégicos e Conjunturais (NEMEC) Natal (RN). E-mail: araujodenilson@hotmail.com .
} 
conclusion: the tertiary sector must be analyzed with strict observance of the concrete conditions of the capital organization within it; in developed countries, the tertiary sector shows greater attractiveness to capital, greater autonomy for growth and modernization when compared to the tertiary sector in the periphery, dependent on international capital and the national state for the production and supply of products and services; despite the structural economic incipience of the tertiary on the periphery of the capitalist system, it was possible to conclude that social or tertiary spaces were and are of fundamental importance for the accumulation of capital in general and that it is becoming, even if in a relative way, an important place of appreciation capital, revenue creation for federative entities and, among other positive points, the creation of formal jobs and information on good amortization mediated as classic system reproduction crises.

Keywords: Tertiary sector; Services; Social division of labor; Industrialization of services; Marxist paradigm.

\section{INTRODUÇÃO}

O setor terciário tornou-se foco central de análises de múltiplas matrizes teóricas. A quantidade e, em muitos casos, a excelente qualidade das análises sobre o setor terciário evidenciam a importância que o mesmo tem para a reprodução do capital e da força de trabalho em sua totalidade, mas, também, para a reprodução do consumidor de forma mais generalizada.

Nas premissas do modo de produção capitalista o setor terciário surgiu como um setor acessório, isto é, com a função de atender às demandas dos setores agrícola e industrial, através de atividades econômicas específicas que estavam para além das competências econômicas dos setores supracitados, ou que oneravam o processo de acumulação de ambos ${ }^{4}$. Neste processo, ele também favorecia o aumento da circulação das mercadorias ao estruturar novos canais de distribuição, o que contribuía para aumentar a escala de produção e acumulação capitalistas. Essas foram as primeiras funções do setor terciário na divisão sócioespacial do trabalho sob o modo de produção capitalista ${ }^{5}$.

É fato amplamente conhecido que a evolução das forças produtivas - novas tecnologias e novas técnicas de produção de mercadorias e serviços -impactaram positivamente no processo de modernização dos setores industrial e agrícola. Ao

\footnotetext{
${ }^{4}$ Como exemplos podem ser citados os serviços cartoriais, de armazenamento e transporte, comércio e tantos outros.

${ }^{5}$ Deve ser observado que a partir da modernização das forças produtivas o setor terciário tornou-se muito mais independente da expansão dos demais setores. Criou novas atividades econômicas e tornou-se mais um importante espaço de acumulação de capital.
} 
longo do tempo, este fenômeno teve rebatimento sobre as demandas do setor terciário, tornando-o absorvedor e demandador de novas tecnologias, ao ponto do mesmo constituir-se em um espaço de acumulação de capital em boa medida autônomo e de fundamental importância para a absorção de novos investimentos. Essa característica essa que passou a prevalecer em meados do século $X X$ principalmente nos países desenvolvidos, adquiriu impulso significativo com o avanço das tecnologias de informação, sobretudo com o advento da internet nas décadas mais recentes. Desse modo, o terciário passou a concentrar importantes atividades econômicas e que proporcionam elevadas taxas de retorno sobre os capitais investidos, com destaque para o crescimento das atividades financeiras, vinculadas aos mercados de crédito e de capitais, cujas dinâmicas de expansão passaram a ter forte impacto sobre os outros setores da economia.

Esse fenômeno acima pode ser visto historicamente como resultado da superação da forma fordista de produção nos países desenvolvidos, levando-os a redesenhar o setor terciário através do deslocamento mais fluido da valorização do capital para o mesmo. A superação da forma de produção fordista, por sua vez, requereu o avanço prévio das forças produtivas em setores estratégicos como os de informática, da eletroeletrônica, dos transístores e de novos materiais (como a fibra ótica e o carbono), da química etc. Essa trajetória teve diferentes graus de intensidade e esteve sujeita à resistência e as fragilidades da organização das classes sociais com o Estado no pacto que consolidou o fordismo em diferentes espaços sociais ${ }^{6}$.

Assim, nos países de capitalismo avançado o desenvolvimento do setor terciário passou a ser um forte indicador de modernização e de prosperidade econômica e social. Não apenas por responder com pontualidade e sofisticação às clássicas demandas dos setores tradicionais da economia, mas, sobretudo, por desenvolver capacidade própria de autoexpansão, criando novas ocupações econômicas, maiores remunerações e melhores qualidades de empregos para uma pequena parcela da força de trabalho. Ou seja, o capitalismo continuou a em acelerado processo de organização da acumulação, remodelando novos espaços de

\footnotetext{
${ }^{6}$ Harvey (1992) em sua obra "Condição pós-moderna" dedicou todo o capítulo 9 explicando minuciosamente a transição do fordismo para uma forma de acumulação mais flexível. Embora não tenha dedicado atenção específica ao setor terciário, a leitura do referido capítulo nos induz a refletir sobre o tipo de terciário que a produção flexível passou a exigir: disperso e articulado geograficamente.
} 
produção, criando novos produtos e com isso criando novas necessidades de consumo. Ao longo do tempo, esse processo foi concretizado através da dispersão geográfica e setorial da produção de mercadorias e serviços. Harvey ao escrever sobre esse fenômeno no final do século vinte (1992: p. 150-151) esclarece que o mesmo não deve ser interpretado como tendência à "desorganização" do sistema de produção capitalista ${ }^{7}$ :

\begin{abstract}
Porque o mais interessante na atual situação é a maneira como o capitalismo está se tornando cada vez mais organizado através da dispersão, da mobilidade geográfica e das respostas flexíveis nos mercados de trabalho, nos processos de trabalho e nos mercados de consumo, tudo isso acompanhado por pesadas doses de inovação tecnológica, de produto e institucional ${ }^{8}$.
\end{abstract}

Em decorrência da perspectiva exposta acima, a hipótese que sustenta esse artigo é que a divisão setorial e geográfica da produção capitalista dos séculos $X X$ e XXI consiste na afirmação de uma tendência intrínseca a expansão do capitalismo, sustentada no processo de divisão internacional do trabalho.

O objetivo do trabalho é observar como as atividades dinâmicas do setor terciário contribuem para a crescente acumulação de capital, à medida que articulam novos espaços, agentes e negócios em diferentes países e recortes territoriais, sobretudo em um contexto no qual elas próprias se tornam fontes de inovações tecnológicas com amplos poderes de impactar tanto direta, quanto indiretamente a produtividade dos outros setores da economia.

O item a seguir será dedicado a tratar a gênese da classificação das atividades econômicas do sistema capitalista segundo os conceitos de Divisão do trabalho nos âmbitos da manufatura e da sociedade, considerando a importância da relação entre essas duas categorias analíticas para o entendimento do capitalismo em geral. No item dois aborda-se a divisão do trabalho e como se expressam os setores econômicos. No item três é enfocada a importância do avanço da divisão social do trabalho e das forças produtivas. Em seguida, são apresentadas as considerações finais.

\footnotetext{
${ }^{7}$ Trata-se da resposta de Harvey (1992) a Offe (1985) e Lash e Urry (1987).

${ }^{8}$ O termo em itálico é do próprio Harvey (1992).
} 


\section{A DIVISÃO DO TRABALHO E AS FORMAS DE EXPRESSÃO SETORIAL DAS ATIVIDADES ECONÔMICAS}

A leitura do Capital, mais precisamente do item quatro no capítulo XII, sugere que Marx procedeu a uma classificação das atividades econômicas que guarda semelhanças com a divisão amplamente difundida baseada em termos setoriais. No referido item, o autor discute a "Divisão do trabalho dentro da manufatura e a divisão do trabalho dentro da sociedade" tendo como fulcro de análise a relação entre as aludidas divisões do trabalho que, segundo afirma: "constitui a base geral de toda a produção de mercadorias" (MARX, 1985a, p. 277).

Marx ao abordar esta relação afirma o seguinte:

Se se considera apenas o próprio trabalho, podemos designar a separação da produção social em seus grandes gêneros, como agricultura, indústria etc., de divisão do trabalho em geral, a diferenciação desses gêneros de produção em espécies e subespécies, de divisão do trabalho em particular, e a divisão do trabalho dentro duma oficina de divisão do trabalho em detalhe (MARX, 1985a, p. 277 , grifos nossos). ${ }^{9}$

Para o autor a classificação da "produção social em seus grandes gêneros", isto é, em agricultura, indústria etc. ${ }^{10}$ guarda coerência com os citados gêneros (ramos, esferas ou "setores") da produção social, vistos por ele como formas de expressão ou de objetivação do trabalho. Portanto, a produção na agricultura apresenta-se como expressão material de coisas úteis formalmente originárias da natureza, embora se constitua, efetivamente, em resultado do trabalho social efetuado nesta atividade. A produção na indústria, por sua vez, tem objetivação também em objetos úteis (mercadorias) e resulta da transformação da natureza com a mediação de uma segunda natureza ou meios de produção produzidos. Os produtos industriais são formal e efetivamente resultado do trabalho humano. Por

\footnotetext{
${ }^{9}$ Marx fez uma citação literal, na nota de rodapé de no 50 , do item quatro, capítulo XII, do Capital, do trecho da obra de SKARBEK, autor no qual baseia a visão exposta acima, que será aqui reproduzida: "Encontramos nos povos que alcançaram certo grau de civilização três espécies de divisão do trabalho: a primeira, a que chamamos de geral, leva à distinção dos produtores em agricultores, manufatores e comerciantes, correspondendo aos três ramos principais do trabalho nacional; a segunda, que se poderia chamar especial, é a divisão de cada ramo de trabalho em espécies [...] a terceira divisão do trabalho, finalmente, que se deveria designar de divisão da operação de trabalho ou divisão do trabalho propriamente dita, é a que se estabelece nos ofícios e profissões separados [...] e que se estabelece na maioria nas manufaturas e nas oficinas" (SKARBEK apud MARX, 1985a, p. 277, grifos nossos).

${ }^{10}$ É razoável supor que o etc. signifique serviços, pois o comércio, constante da classificação de Skarbek considerada por Marx, conforme registra a nota de rodapé anterior, é atividade de circulação ou de distribuição da produção material.
} 
sua vez, os serviços (conforme suposto) não têm objetivação material. São, portanto, atividade humana que resulta em produção não material ainda que, em alguns casos, se fixe em objetos.

É importante observar que a produção social segundo gêneros expressa o trabalho social em geral e, portanto, não tem a ver com uma forma social especifica. Segundo Marx, dentro da família e da tribo é que se origina "uma divisão do trabalho [...] sobre uma base puramente fisiológica", isto é, baseada em diferenças de sexo e idade. Além disso, considera que esta amplia-se com "a expansão da comunidade", "o crescimento da população" e "o conflito entre [...] tribos e a subjugação de uma tribo por outra". Portanto, em determinado momento, o intercâmbio de produtos ocorre não a partir do contato autônomo entre "pessoas privadas", mas entre famílias, tribos e comunidades, ou seja, em função de diferenças de "modo de produção, modo de vida e de produtos". É a partir destes contatos que passa a ocorrer "a transformação progressiva desses produtos em mercadorias". Para o autor, "O intercâmbio não cria a diferença entre as esferas da produção, mas as coloca em relação e as transforma em ramos mais ou menos interdependentes de uma produção social global”. Ademais, acrescenta Marx (1985a, p. 277) que

Onde a divisão fisiológica do trabalho constitui o ponto de partida, os órgãos particulares de um todo conexo desprendem-se uns dos outros [...] e se autonomizam até o ponto em que a conexão entre os diferentes trabalhos é medida pelo intercâmbio dos produtos como mercadorias.

É por isso que, segundo Marx (1985a, p. 278), "A base de toda divisão do trabalho desenvolvida e mediada pelo intercâmbio de mercadorias é a separação entre a cidade e o campo". O que se encontra subjacente a tal afirmação é que a divisão do trabalho dominante no campo, ao menos até que a divisão do trabalho desenvolvida se afirme, é de base fisiológica e produtora de mercadorias apenas fortuitamente. Então, a aludida separação, que a princípio sugere a existência de uma dicotomia campo-cidade, têm, por um lado, muito mais o caráter de rompimento de uma ordem baseada em laços de parentesco e proximidade e, por outro, a afirmação de uma nova "ordem" fundada na relação entre possuidores de mercadorias. Segue, pois, que o locus, por excelência, dessas relações é a cidade e o objeto que domina a mediação das relações sociais é a mercadoria. Desse modo, a divisão do trabalho que passa a atuar na sociedade ocorre entre produtores 
independentes que se conectam através do intercâmbio dos seus produtos como mercadorias.

No contexto da produção capitalista, em que produção e circulação constituem-se em pressuposto, é necessário que a divisão social do trabalho "tenha amadurecido até certo grau de desenvolvimento" para propiciar o desenvolvimento da divisão manufatureira do trabalho. Mas, ao mesmo tempo em que esta se desenvolve, exerce "efeito recíproco" sobre a "divisão social do trabalho". Em contexto de "diferenciação dos instrumentos de trabalho diferenciam-se cada vez mais os ofícios que produzem estes instrumentos" (MARX, 1985a, p. 278). Portanto, se a divisão social do trabalho caracteriza-se pela existência de produtores independentes que produzem mercadorias, a divisão manufatureira do trabalho caracteriza-se pela presença de trabalhadores parciais que apenas através da atuação conjunta conseguem produzir uma mercadoria.

Segundo Marx (1985a, p. 280), a divisão manufatureira do trabalho pressupõe além da concentração dos meios de produção, "a autoridade incondicional do capitalista sobre os seres humanos transformados em simples membros de um mecanismo global que a ele pertence", enquanto, por sua vez, a divisão social do trabalho "confronta produtores independentes de mercadorias, que não conhecem nenhuma outra autoridade senão a da concorrência".

\section{A IMPORTÂNCIA DO AVANÇO DAS FORÇAS PRODUTIVAS E DA DIVISÃO SOCIAL DO TRABALHO}

O desenvolvimento da divisão manufatureira do trabalho com seus rebatimentos na divisão social do trabalho é, ao mesmo tempo, a constituição de "gêneros", "ramos", "esferas", "espécies" e "subespécies" da produção separados, porém interdependentes. Para o avanço da divisão do trabalho na manufatura, com impactos inequívocos na divisão social do trabalho, foi fundamental o desenvolvimento da maquinaria, ou da máquina-motriz, do mecanismo de transmissão e da máquina-ferramenta ou máquina de trabalho. Afirma Marx (1985b, p. 08) que: "É desta última parte da maquinaria, a máquina-ferramenta, que se origina a revolução industrial do século XVIII". A partir de então, o homem passou a desenvolver um papel de vigia e de assistente da máquina que tornou-se um organismo de produção "inteiramente objetivo". Desse modo, "O revolucionamento 
do modo de produção numa esfera da indústria condiciona seu revolucionamento nas outras" articulando-se entrelaçadamente em um processo global (MARX, 1985b, p. 15). A título de exemplo, cita-se o caso da mecanização da fiação que 'exigiu' a mecanização da tecelagem e que juntas condicionaram uma revolução mecânica e química nas fases de branqueamento, estampagem e tinturaria.

$\mathrm{Na}$ verdade, modificações ocorridas em segmentos produtivos específicos acabam por se refletir numa escala de abrangência muito mais ampla. Assim, em verdadeiro efeito de transbordamento "a revolução no modo de produção da indústria e da agricultura exigiu também uma revolução nas condições gerais do processo de produção social, isto é, nos meios de comunicação e transporte" (MARX, 1985b, p. 15). Ou seja, os processos de trabalho e de produção nos distintos segmentos industriais atuam de forma articulada e interdependente em processos de trabalho e de produção que ocorrem em outras esferas produtivas, bem como nas esferas da distribuição e da circulação da riqueza social. Portanto, a divisão manufatureira do trabalho - ou divisão propriamente capitalista - e a divisão social do trabalho - ou divisão do trabalho em sentido geral - coexistem e interinfluenciamse permanentemente.

A produção e a divisão do trabalho especificamente capitalistas foram profundamente transformadas em decorrência do processo revolucionário de fabricação de máquinas-ferramentas ou de constituição de um setor produtor de meios de produção. Segundo Marx, (1985b, p. 16) a grande indústria teve de se apoderar do seu meio de produção característico, a máquina, e "produzir máquinas por meio de máquinas", criando, dessa forma, "sua base técnica adequada". Deste processo resultou, no interior da indústria, uma progressiva distinção entre um setor produtor de bens de consumo e de um setor produtor de bens de produção e, por conseguinte, o aprofundamento da divisão do trabalho envolvido nas produções de bens de consumo e de bens de produção.

Nos capítulos destinados ao estudo da "Reprodução simples" e da "Acumulação e reprodução ampliada" do capital social total Marx, dividiu a produção social em dois grandes departamentos: o departamento I, produtor de meios de produção, que produz mercadorias formalmente capazes de participar do consumo produtivo e o departamento II, produtor de bens de consumo, que produz mercadorias aptas a participar do consumo individual das classes trabalhadora e capitalista. Embora o propósito do autor nos capítulos em destaque fosse o estudo 
do processo de produção e de circulação do capital social total levando em consideração as inter-relações setoriais tanto do valor quanto da materialidade do produto-mercadoria anual, é importante destacar que o fez através de um recurso analítico que inspira ainda na atualidade a classificação das atividades industriais (MARX, 1985c).

Do exposto, segue que, tendo por base a divisão da produção social nos referidos departamentos, é possível dividir a produção industrial em um setor (forma modificada de departamento) de bens de consumo e em um setor produtor de bens de capital. O setor de bens de consumo pode ainda ser subsetorializado - ou subdepartamentalizado - em bens de consumo não duráveis (aproximação do subdepartamento produtor de meios de subsistência necessários) e em bens de consumo duráveis (aproximação do subdepartamento produtor de artigos de luxo). De outra parte, o setor de bens de produção pode ser dividido em bens de capital (para especificar o setor de máquinas, equipamentos e instalações) e bens intermediários (para especificar os bens industriais que passarão por modificações até tornarem-se bens finais). Embora deva-se ressaltar que as revoluções tecnológicas ocorridas desde Marx até a contemporaneidade tenham dificultado, consideravelmente, a classificação de algumas atividades entre indústria e serviços, é importante ressaltar que o uso de classificações próximas à acima apresentada, sobretudo no caso de análises sobre a indústria, reforça a pertinência e a vitalidade da mesma.

Embora Marx tenha identificado um forte caráter revolucionário do capital para modificar processos produtivos para além da indústria, não mostrou-se convicto quanto às possibilidades do capital se apoderar dos serviços pela suposta impossibilidade de promover a subsunção formal do trabalho nessa atividade. Entretanto, no campo do marxismo no século vinte passou a ser defendido que a posição de Marx quanto à impossibilidade de atuação capitalista nos serviços não se sustenta diante das evidências. Singer (1981) assevera que houve uma "verdadeira industrialização de certos serviços" dentre os quais destaca os de comunicações, algumas "artes performativas" e alguns "serviços pessoais". Afirma Singer (1981, p. 117): "A sua evidente subordinação real ao capital [...] e sua grande significação econômica no presente de modo algum permitem que sejam negligenciados". Posições semelhantes são também defendidas por alguns outros autores tais como OLIVEIRA, (1978), MANDEL (1985) e LIPIETZ (1988), dentre outros. 
Mandel (1985) ressalta que o desenvolvimento capitalista encontra-se associado ao avanço das forças produtivas e à intensificação da divisão do trabalho ${ }^{11}$. Com relação ao último processo, Fuchs (2016) aborda a importância da divisão do trabalho em escala internacional para o conceito de imperialismo ${ }^{12}$. Para o referido autor, pensadores da tradição marxista, mais precisamente, Lenin, Bukharin, and Luxemburg all saw the international division of labor as a central feature of imperialism. FUCHS (2016). E uma vez que esses teóricos enxergaram no imperialismo "a força e o instrumento do capitalismo" é possível observar as conexões que existem entre divisão internacional do trabalho e o avanço da acumulação de capital a partir de bases territoriais, em que se observa a articulação centro-periferia do sistema.

\begin{abstract}
Although Lenin, Bukharin, and Luxemburg differed politically on several aspects of imperialism, especially on questions concerning the role of nationalism in class struggles and liberation, national self-determination, and the use of foreign markets in capitalism, it is clear that for all three theorists, the periphery is not just a source of resources and a market for selling commodities, but is also embedded in an international division of labor. As part of this division, the exploitation of workers in the periphery enables the export and appropriation of surplus value by large companies. FUCHS (2016, p. 04).
\end{abstract}

Em se tratando da perspectiva que associa o avanço das forças produtivas à intensificação da divisão do trabalho para o desenvolvimento capitalista, Mandel (1985) pôs em destaque que até as vésperas da Segunda Guerra Mundial, a especialização e a divisão do trabalho verificadas na agricultura ocorreram a uma velocidade inferior à constatada na indústria. A partir de então, a agricultura teria passado por profundas mudanças, a princípio com a utilização de máquinas e produtos químicos e, em seguida, com a sua conversão em setores industriais como foi o caso da agroindústria.

No que concerne às atividades terciárias, ênfase foi dada ao fato de que nos períodos relativos à 'livre' concorrência e ao imperialismo clássico a penetração do

\footnotetext{
${ }^{11}$ Mandel publicou "O capitalismo tardio" em 1972 considerando que se tratava de uma nova fase do desenvolvimento capitalista. A primeira fase teria sido correspondente ao "capitalismo concorrencial" e que teria vigorado até o terceiro quarto do século XIX. A segunda fase, correspondente ao "capitalismo monopolista", teria sido iniciada no último quarto do século XIX e encontrava-se em vigor à época da publicação do citado livro. O "capitalismo tardio" era considerado, então, uma fase do "capitalismo monopolista" que tivera início no imediato pós-Segunda Guerra.

12 De acordo com Fuchs (2016), A century has now passed since Lenin's Imperialism, the Highest Stage of Capitalism (1916) and Bukharin's Imperialism and World Economy (1915), as well as Rosa Luxemburg's 1913 Accumulation of Capital, all spoke of imperialism as a force and tool of capitalism.
} 
capital nos setores intermediários ocorreu no processo de circulação, sendo os setores privilegiados os de transporte e os sistemas de comércio e de crédito. Neste momento, a exemplificação foca o caso do financiamento de bens duráveis nos EUA. Portanto, contestando a tese do pós industrialismo ${ }^{13}$, Mandel (1985, p. 271) destaca que o período do capitalismo tardio identifica-se com o da "industrialização generalizada universal pela primeira vez na história". Segundo este autor, tal processo intensificou-se profundamente na agricultura, mas "A industrialização da esfera de reprodução constitui o ápice desse processo". Os setores destacados foram os da produção e distribuição de programas televisivos, filmes e documentários (MANDEL, 1985, p. 272).

Para Mandel, a penetração do capital nas esferas da circulação e dos serviços proporcionou aumento da mais-valia pelo fato de exercer as seguintes funções: assumiu funções do capital industrial; acelerou o tempo de rotação do capital produtivo; reduziu custos de circulação e ampliou os limites da produção de mercadorias. Segundo sua abordagem, a supercapitalização característica do capitalismo tardio obtida pelo capital industrial que não encontrava valorização na própria indústria foi o pré-requisito essencial para a expansão dos serviços. Desse modo, essa fase de expansão do terciário teria sido também o da constituição de uma "sociedade de consumo" que, em boa medida, promoveu a incorporação de parcela considerável dos trabalhadores. A experiência histórica vivenciada pelos trabalhadores teria englobado não somente 0 acesso aos bens de consumo imediato, mas também aos artigos considerados de luxo e as esferas da cultura e do lazer. Em tal período, as conquistas obtidas pelos trabalhadores foram supridas, em parte, às expensas dos ganhos capitalistas. Sendo assim, os trabalhadores puderam adquirir poder de compra para participar da "reprivatização da esfera do lazer". Mandel (1985, p. 276)

Mandel considerou a investida do capital nos serviços "na melhor das hipóteses, um mal menor", pois a ideia subjacente ao argumento é que a mais-valia que provem dos serviços constitui efetivamente dedução da mais-valia criada pelo capital produtivo. Então, numa "sociedade de serviços" o trabalho teria se transformado em "trabalho assalariado improdutivo". Esse movimento de

\footnotetext{
${ }^{13}$ Daniel Bell formulou tal abordagem na obra intitulada "O Advento da Sociedade Pós-industrial. São Paulo. Cultrix. 1974". Um bom resgate deste debate é encontrado em "KUMAR, K. Da sociedade PósIndustrial à Pós-Moderna. Rio. Zahar. 1997".
} 
terciarização significava para Mandel "o prenúncio do fim do capitalismo" (MANDEL, 1985, p. 285). A obra de Mandel lançou luzes sobre a realidade de países de capitalismo central no período do pós-Segunda Guerra até o fim dos anos 1960. Não obstante, vale ressaltar que o autor superestimou o avanço tecnológico ocorrido no período, tendo como base energética a energia atômica ao imaginá-la como a fonte possivelmente dominante no futuro. Outro aspecto a ser ressaltado é que embora se possa afirmar que o capitalismo terá um fim, não tem sentido identificar o prenúncio de tal fim à ocorrência da 'exploração' capitalista dos serviços ou ao descolamento da 'esfera' financeira em relação à esfera produtora do conteúdo material da riqueza.

É possível passar da referência a países de capitalismo central para países periféricos mantendo a ideia de interdependência setorial ${ }^{14}$. É importante destacar que, segundo a abordagem aqui utilizada, o estudo do terciário é realizado negando a perspectiva que se mantém presa a esquemas com pretensões evolutivas e que indica que a elevação da renda per capita ao longo do tempo, em todas as partes, promoverá a expansão das atividades e dos empregos terciários pela inelutável elevação da demanda por serviços. Para conferir evidência em contexto de economias periféricas à abordagem de que o terciário deve ser compreendido na sua relação "com o processo de acumulação de capital em condições históricas concretas", deve ser destacado que antes de passarem por processos de industrialização, vários países coloniais tiveram os seus terciários formados a partir de condicionamentos decorrentes dos complexos agroexportadores que se constituíam nos segmentos econômicos dinâmicos, através dos quais tais países participavam da divisão do trabalho em escala mundial. Neste contexto, "as economias coloniais eram vastas aglomerações urbanas" (OLIVEIRA, 1978, p. 147).

Advindo o processo de industrialização, este promoveria mudanças profundas nas relações entre os setores produtivos. Por isso, quando as citadas economias passaram a empreender processos de industrialização, por sobre um terciário voltado à exportação, "cria-se agora um cuja função é sustentar a expressão urbana dos processos de industrialização". Então, a produção dos grandes espaços urbanos

\footnotetext{
${ }^{14}$ A classificação centro-periferia ganhou grande audiência no âmbito da produção teórica cepalina. $\mathrm{Na}$ formulação original dizia respeito aos países produtores de produtos industrializados (centro) e a países produtores de bens primários (periféricos). Em decorrência de mudanças na órbita produtiva, a classificação é enfocada pela ótica da intensidade dos fatores. Assim, o centro é constituído pelos países que produzem bens e serviços com maior intensidade de capital e tecnologia, enquanto a periferia é produtora de bens e serviços que dependem fundamentalmente de recursos naturais e força de trabalho.
} 
latino-americanos ocorreu num quadro em que a força de trabalho deveria estar disponível para atuar nos novos postos da indústria, na expansão horizontal dos serviços e na integração do exército industrial de reserva. O conflito social que caracterizou tal processo é, portanto, a chave para a compreensão da divisão social do trabalho (OLIVEIRA, 1978, p. 148).

$\mathrm{Na}$ realidade, tratava-se de uma nova divisão internacional do trabalho, marcada por mudanças estratégicas dos grandes oligopólios mundiais, em consonância com as orientações políticas locais, que propiciou à implantação de empreendimentos industriais em países que se caracterizaram pela produção de bens primários no contexto da primeira divisão internacional do trabalho.

No quadro da nova divisão do trabalho, alguns países latino-americanos experimentaram processos de industrialização baseados em setores industriais modernos e com maior complexidade tecnológica, promovendo a acentuação da heterogeneidade produtiva e social preexistente. No caso dos países em que foram implantados segmentos industriais modernos, constituíram-se segmentos de serviços com atividades complementares às atividades produtivas ou segmentos vinculados à distribuição dos bens. De outra parte, segundo Dedecca e Montagner (1992, p. 06), na maioria dos "países ampliaram-se as atividades ligadas à constituição de um aparelho de Estado com funções mais complexas e de atividades menos organizadas, impulsionadas pelo processo de urbanização crescente". No contexto dos processos de industrialização em pauta, alguns países experimentaram processos de expansão econômica fundados na indústria, tendo o terciário também assumido importante papel para a composição do produto interno e para a ocupação, ao mesmo tempo em que houve avanços na estruturação dos mercados de trabalho, não obstante a permanência da heterogeneidade social.

Esgotado o 'ciclo' expansivo fundado na tecnologia da Segunda Revolução Industrial, foi paulatinamente sendo gestada uma nova divisão do trabalho em escala mundial. Se é correto afirmar que a nova divisão do trabalho tem o comando exercido pela dimensão financeira, papeis fundamentais são também exercidos pelo processo de reestruturação empresarial e pela nova Revolução tecnológica, em curso, fundada na microeletrônica, na informática e na comunicação (CANO, 1995; POCHMANN, 2001) e pelo avanço da economia digital. Fuchs (2016) chama atenção para o seguinte aspecto: 
Global communications, in the form of the telegraph and international news agencies, already played a role in imperialism by the time of the First World War, helping to organize and coordinate trade, investment, accumulation, exploitation, and war. A hundred years later, qualitatively different means of information and communication such as supercomputers, the Internet, laptops, tablets, mobile phones, and social media have emerged. But just like the labor of workers in the periphery during earlier stages of imperialism, the production of information and information technology is part of an international division of labor, one that continues to shape modes of production, distribution, and consumption

O novo momento do capitalismo tem sido marcado principalmente pelo deslocamento diário de fluxos de capitais de curto prazo. A expansão da indústria na periferia tem sido focada principalmente na produção de partes menos complexas dos produtos e fundadas em tarefas rotineiras. Mais recentemente, na constituição das cadeias produtivas que passaram a operar em escala mundial, os serviços têm assumido papel primordial.

As atividades que se caracterizam por comando e elaboração e que se constituem em apoio à produção têm se concentrado fortemente nos países do centro do sistema. Faz-se necessário esclarecer que o centro do capitalismo atual não é o mesmo da época do pós-guerra já que a China e alguns países asiáticos parecem ter entrado, enquanto Inglaterra, Itália parecem fortes candidatos a perderem o status de países centrais. De outra parte, a expansão da indústria na periferia tem focado principalmente a produção de partes menos complexas dos produtos e fundadas em tarefas rotineiras. Mais recentemente, na constituição das cadeias produtivas que passaram a operar em escala mundial, os serviços têm assumido papel primordial com as novas tecnologias, viabilizando, inclusive, 0 deslocamento diário de fluxos de capitais de curto prazo. De outra parte, é no âmbito dessa nova divisão do trabalho que os países da periferia, dentre os quais figuram os da América Latina, têm experimentado abertura econômica e financeira e com frequência reduzidas taxas de expansão da atividade econômica.

A trajetória dos serviços no novo contexto continuou relacionada ao movimento dos segmentos econômicos mais dinâmicos, em particular da forma como empreendam suas reestruturações, ao movimento do próprio processo de urbanização ao implicar em novos requerimentos de infraestrutura tanto em função dos processos produtivos quanto de serviços coletivos, e ainda à forma de atuação do poder público ante as novas demandas. 
É fato que todos os países do mundo encontram-se integrados de alguma maneira ao processo de divisão do trabalho, sobretudo em decorrência da crescente mundialização ocorrida nas últimas décadas, sendo que as formas de inserção nesta divisão do trabalho encontram-se relacionadas a fatores tecnológicos, econômicos e políticos. Ao mesmo tempo, internamente a cada país ocorre também uma divisão heterogênea do trabalho e da produção que expressa os conflitos sociais e a organização política existente.

O curso dos acontecimentos poderá ocorrer sob coordenação do poder público com vistas a fazer com que os resultados evitem grande aprofundamento das heterogeneidades existentes ou poderá ser conduzido seguindo a lógica privada dos retornos em prazo curto.

As evidências revelam que no caso dos países da América Latina tem ocorrido continuidade da exportação de commodities de origem primária, ao mesmo tempo em que tem ocorrido elevação da exportação de bens industriais com baixo valor agregado. Na realidade, tal processo revela que a estrutura produtiva da região não logrou êxito quanto à internalização dos processos produtivos fundados na tecnologia da nova Revolução tecnológica em curso.

No caso dos serviços, predominam aqueles voltados ao consumo pessoal e os serviços sociais, em boa medida, sob responsabilidade estatal e no caso dos serviços auxiliares à produção, ou são prestados por empreendimentos situados em países centrais ou principalmente por estabelecimentos situados nas áreas concentradoras da estrutura econômica de cada país e que adquiriram capacidade de atender a demandas em escala nacional.

Quanto aos serviços integrantes da estrutura verticalizada das empresas, podem impactar no valor da produção e no nível de ocupação do terciário, em decorrência do recorrente processo de terciarização na contemporaneidade. Portanto, o ritmo de expansão do terciário decorrerá de demandas empresariais por serviços produtivos e distributivos, dos gastos efetivados principalmente pelo poder público para garantir o provimento de serviços sociais demandados pela população crescente e, por fim, da elevação do poder aquisitivo e sobretudo de decisões de gastos de indivíduos e famílias com serviços pessoais. 


\section{CONSIDERAÇÕES FINAIS}

Como ficou evidente no presente trabalho, a classificação das atividades econômicas em diferentes departamentos e setores consta dos textos de economia política do século XIX, notadamente dos textos de Karl Marx, especificamente da obra "O Capital". Todavia, deve ser observado que as exaustivas reflexões de Marx sobre os setores industrial e agrícola não se estenderam ao setor terciário. Esse fato levou os críticos de Marx a propalarem que inexistia em seu construto teórico a possibilidade do capital assumir a acumulação do capital no setor nesta perspectiva teórica.

Mandel e Singer (1981) dedicaram especial atenção ao tema enfatizando que muitas atividades (serviços) que são desenvolvidas no setor terciário experimentaram verdadeiras transformações "industriais" tais como as artes, as comunicações etc. Fato evidenciado nas últimas décadas com o avanço da internet, permitindo que grandes empresas do setor terciário operassem seus negócios em escala mundial, através das plataformas tecnológicas globais, capacitando-as a promover um processo de acumulação de capital que transformaram-nas nas maiores empresas do mundo, a exemplo da Google, Facebook, Amazon. MOROZOV (2018).

Observou-se que historicamente, o avanço das forças produtivas viabilizou profundas transformações no setor terciário, modernizando a produção e a oferta de "antigos" e novos bens e serviços, que tanto no centro do sistema capitalista quanto na periferia passaram a ser essenciais à reprodução do trabalho, do capital e do Estado, mantendo, evidentemente, suas características estruturais específicas dependendo do desenvolvimento da economia de cada país.

Com o surgimento de novas tecnologias, notadamente nas áreas da informática, microeletrônica e comunicação em geral, o setor terciário ampliou sua capacidade de oferta de novos serviços diminuindo o tempo de rotação do capital no setor e possibilitando a realização de negócios e investimentos em tempo real. As mudanças institucionais derivadas da integração de inúmeros países à globalização financeira, combinaram-se à recente expansão da economia digital, operada pelas grandes empresas do setor terciário e que emergiram com grande força a partir da grande crise de 2008. Morozov (2018). 
Este ambiente potencializou a ampla movimentação do capital, articulando diferentes espaços nacionais e relações de produção, inclusive as pré-capitalistas ao redor do planeta , enquanto promovia a superação da forma de acumulação fordista e impunha ao mesmo tempo aos ramos dinâmicos do setor terciário nos países desenvolvidos, a capacidade de ditar inovações tecnológicas aos demais setores o status de a induzir as novas tendências de produção e consumo de bens e serviços de última geração tecnológica.

Cabe registrar, porém, que no que se refere ao setor terciário de regiões e países periféricos, deve-se ficar atento para o fato de que em tais realidades o setor terciário, salvo raríssimas exceções, tem se revelado pouco produtivo, pouco inovador e concentrador de alta e crescente informalidade. Quanto aos serviços, observa-se a predominância daqueles voltados ao consumo pessoal e sociais, com preponderância da produção e da oferta pelo Estado em países em desenvolvimento. No que tange aos serviços auxiliares à produção, deve-se atentar para o fato de que grande parte é prestada por organizações empresariais sediadas fora dos países e regiões periféricas, ou por massas de capitais presentes em restritas áreas periféricas concentradoras de estrutura econômica com capacidade de atender as demandas locais.

Em que pese o fato dessa realidade ter sido relativamente modificada a partir da globalização econômica, poucos foram os países da periferia que estruturaram seus setores terciários a partir da absorção de novas tecnologias, exceção dos restritos espaços dos terciários onde o capital financeiro, sob as mais diversas roupagens (fundos de investimento, financeiras, seguradoras, imobiliárias etc.), criou e manteve atividades de padrão internacional.

\section{REFERÊNCIAS BIBLIOGRÁFICAS}

BELL, D. O Advento da Sociedade Pós-Industrial. São Paulo. Cultrix. 1974.

CANO, Wilson. Reflexões sobre a nova (des)ordem internacional. 4 ed. Campinas-SP: Editora da Unicamp; São Paulo: Fapesp, 1995.

DEDECCA, Cláudio S. e MONTAGNER, Paula. Crise econômica e desempenho do terciário. São Paulo em perspectiva, São Paulo, 6(3): 2-15, jul./set., 1992.

FUCHS, Christian. Digital Labor and Imperialism. Monthly Review.Jan. 01/2016.

HARVEY, David. Condição pós-moderna. São Paulo: Ed. Loyola, 1992.

KUMAR, K. Da sociedade Pós-Industrial à Pós-Moderna. Rio. Zahar. 1997. 
LASH, S. e URRY, J. The end of organized capitalism. Oxford, 1987.

LIPIETZ, Alain. O capital e seu espaço. São Paulo: Nobel, 1988.

MANDEL, Ernest. O capitalismo tardio. 2. ed., São Paulo: Nova Cultural, 1985. (Os Economistas).

MARX, Karl. O capital: crítica da economia política. 2. Ed., São Paulo: Nova Cultural, 1985b. (Coleção os Economistas, L1, t1).

MARX, Karl. O capital: crítica da economia política. 2. Ed., São Paulo: Nova Cultural, 1985c. (Coleção os Economistas; L1, t2).

MARX, Karl. O capital: crítica da economia política. 2. Ed., São Paulo: Nova Cultural, 1985d. (Coleção os Economistas, L2).

MOROZOV, Evgeny. Big Tech: a ascensão dos dados e a morte da política. São Paulo: Ubu Editora, 2018. /192 pp. / Coleção Exit, 1984.

OFFE, C. Disorganized capitalism. Oxford, 1985.

OLIVEIRA, Francisco de. O terciário e a divisão social do trabalho. In: Estudos Cebrap, n. 24. São Paulo: Vozes, 1978.

POCHMANN, Márcio. O emprego na globalização: a nova divisão internacional do trabalho e os caminhos que o Brasil escolheu. São Paulo: Boitempo, 2001.

SINGER, Paul. Trabalho produtivo e excedente. In: Revista de Economia Política, vol. 1, n. 1, jan-mar. São Paulo: Brasiliense, 1981. 